Ewa Półtorak

Uniwersytet Śląski w Katowicach

ewa.poltorak@us.edu.pl

Jarosław Krajka

Uniwersytet Marii Curie-Skłodowskiej w Lublinie

jarek.krajka@wp.pl

\title{
E-LEARNING W KSZTAŁCENIU KOMPETENCJ MIĘDZYKULTUROWYCH NA POZIOMIE UNIWERSYTECKIM - W STRONĘ KODEKSU DOBREJ PRAKTYKI
}

Developing intercultural competences on the university level in e-learning: towards a code of good practice

The purpose of the present paper is to describe selected self-study learning environments focused on target language culture for university students. After reviewing introductory concepts of intercultural competence, the results of the external audit of a corpus of e-learning courses will be presented. Conclusions reached may pave the way for future development of interactive materials for intercultural instruction.

Keywords: ICT, e-learning, foreign language teaching/learning process, Intercultural Communicative Competence

Słowa kluczowe: TIK, e-learning, proces nauczania/uczenia się języków obcych, kompetencja międzykulturowa

\section{Wstęp}

W dzisiejszych czasach nowe technologie informacyjno-komunikacyjne (TIK) zyskują coraz większe znaczenie. Towarzyszą one naszym działaniom w praktycznie 
każdej dziedzinie naszego życia i mogą być uważane za jeden z najważniejszych, a na pewno jeden z najbardziej rozpoznawalnych symboli współczesnej cywilizacji. Smartfony, tablety, netbooki, palmtopy, laptopy i inne urządzenia multimedialne stały się nieodłącznym atrybutem codziennego życia dla większości ludzi, którzy wykorzystują je nie tylko w celach prywatnych, ale i zawodowych. Nie dziwi zatem fakt, że także w systemie edukacyjnym, którego jednym z zasadniczych celów jest przygotowanie jego odbiorców do aktywnego i twórczego udziału w życiu współczesnego społeczeństwa, a więc społeczeństwa mniej lub bardziej swobodnie korzystającego z różnego rodzaju technologii cyfrowych, nowoczesne narzędzia technologiczne odgrywają coraz ważniejszą rolę. Stopniowo przestają one być traktowane jako atrakcyjne gadżety, których głównym, a czasami jedynym zadaniem jest uatrakcyjnienie poszczególnych zajęć, co jeszcze nie tak dawno miało miejsce w praktyce dydaktycznej. Dotyczy to także procesu nauczania/uczenia się języków obcych, w którym wykorzystanie technik opartych na technologiach komputerowych, w tym technik kształcenia na odległość (tzw. e-learningu), może pełnić różnorodne funkcje. Wśród nich można wymienić wspomaganie rozwoju kompetencji międzykulturowych uczniów, który to proces może bazować m.in. na mniej lub bardziej rozbudowanych modułach czy też pełnych kursach e-learningowych, samodzielnie zaprojektowanych przez nauczyciela/autora kursu. Celem niniejszego artykułu jest analiza przykładowych rozwiązań tego rodzaju, przedstawiona w kontekście nauczania/uczenia się języków obcych na poziomie uniwersyteckim.

\section{Kształcenie kompetencji międzykulturowych w procesie nauczania/ uczenia się języków obcych}

Badanie kompetencji międzykulturowych należy do jednych z najbardziej aktualnych, a zarazem jednym z najczęściej podejmowanych tematów przez współczesnych glottodydaktyków (por. np. Banach, 2003; Bandura, 2007; Chłopek, 2009; Mackiewicz, 2005; Mackiewicz, 2009; Mihułka, 2012a; Mihułka, 2012b; Mihułka, 2014; Siek-Piskozub, 2012; Torenc, 2007; Wilczyńska, 2002; Zając, 1997; Zając, 2012; Żydek-Bednarczuk, 2012; Żydek-Bednarczuk, 2015; Żylińska, 2003). Na zainteresowanie tym obszarem badawczym wpływają promowane przez Radę Europy od ponad dekady idee wielojęzyczności oraz wielokulturowości. Co za tym idzie, potrzeba stworzenia systemu edukacji językowej, sprzyjającego rozwojowi postawy otwartości wobec przedstawicieli odmiennych od własnej grup językowo-kulturowych, stanowi jeden z priorytetów współczesnej edukacji językowej.

W ogólnym znaczeniu kompetencja międzykulturowa, nazywana również interkulturową lub kulturową (por. Mackiewicz, 2005; Żydek-Bednarczuk, 2012), może być rozumiana jako „znajomość podobieństw i różnic między stylami życia 
i poglądami charakterystycznymi dla różnych kultur" oraz umiejętność wykorzystania tej wiedzy w konkretnych sytuacjach komunikacyjnych (Bandura, 2007: 57). Przekłada się to na dobrą znajomość zagadnień umożliwiających zachowanie tzw. „społecznego wymiaru komunikacji”, do których można zaliczyć m.in. znajomość wyznaczników relacji społecznych, konwencji grzecznościowych, nośników tzw. mądrości ludowej, różnych rejestrów wypowiedzi, dialektów czy odmian regionalnych (ESOKJ, 2003: 106-109). Innymi słowy kompetencja ta pozwala na kulturowo adekwatne użycie języka obcego do danego kontekstu sytuacyjnego. Ma ona zatem bezpośredni wpływ na jakość prowadzonych w danym języku działań komunikacyjnych, gdyż pozwala na dostosowanie wybranych treści językowych do odpowiednich schematów interakcyjnych, właściwych dla danej społeczności kulturowej. W związku z tym kompetencja ta jest uznawana przez współczesnych badaczy za jeden z kluczowych komponentów skutecznego porozumiewania się w języku obcym, bez którego „efektywność komunikowania się w [danym] języku może być zagrożona" (Mackiewicz, 2005: 10). Nie dziwi zatem fakt, że rozwój kompetencji międzykulturowej stanowi w dzisiejszych czasach jeden z najważniejszych celów kształcenia językowego.

Z praktycznego punktu widzenia kompetencja międzykulturowa może być rozpatrywana jako zdolność „zachowania się adekwatnie i umiejętnie w momencie zetknięcia się z działaniem, postawą i oczekiwaniami przedstawicieli obcych kultur" (Banach, 2003: 3). W jej skład wchodzą zatem nie tylko umiejętności językowe sensu stricto, ale również pewne czynniki osobowościowe, wykraczające poza ramy klasycznie rozumianej komunikacji językowej. Odwołując się do terminologii zaproponowanej przez autorów Europejskiego Systemu Opisu Kształcenia Językowego (2003), można stwierdzić, że kompetencja międzykulturowa łączy w sobie elementy zarówno należące do tzw. językowych kompetencji komunikacyjnych, jak i te utożsamiane z tzw. kompetencjami ogólnymi. Te ostatnie są wykorzystywane przez poszczególnych użytkowników danego języka w różnych sytuacjach życia codziennego (nie tylko tych bezpośrednio związanych z działaniami językowymi) i obejmują szerokie spektrum ich wiedzy (savoir), umiejętności praktycznych (savoir-faire), indywidualnych uwarunkowań osobowościowych (savoir-être) czy też umiejętności uczenia się (savoir-apprendre). Wśród wymienionych grup czynników wchodzących w skład kompetencji ogólnych użytkowników języka można wyróżnić co najmniej cztery komponenty, które w bezpośredni sposób wiążą się z kształceniem kompetencji międzykulturowej. Są to:

1. wiedza socjokulturowa, definiowana jako „wiedza o społeczeństwie i kulturze społeczności, która posługuje się danym językiem"; 
2. Wrażliwość interkulturowa, określana jako „wiedza, świadomość i rozumienie relacji (podobieństw i różnic) między światem społeczności pochodzenia a światem społeczności języka docelowego";

3. zbiór umiejętności interkulturowych, obejmujących „umiejętność dostrzegania związku między kulturą własną a obcą”, „umiejętność dokonywania właściwych wyborów strategii i ich odpowiedniego użycia w kontakcie z osobami z innych kultur”, „umiejętność pośredniczenia między kulturą własną a obcą”, jak i „umiejętność przezwyciężania stereotypów”;

4. tzw. „osobowość interkulturowa”, którą kształtują takie czynniki indywidualne jak postawa ciekawości i otwartości wobec obserwowanych zjawisk interkulturowych oraz umiejętność ich obiektywnej (tzn. pozbawionej stereotypowych uprzedzeń) interpretacji czy też „skłonność do relatywizacji własnego kulturowego punktu widzenia oraz związanego z nim kulturowego systemu wartości" (ESOKJ, 2003: 94-99).

Kompetencję międzykulturową kształtują zatem czynniki należące do trzech różnych wymiarów:

1. kognitywnego, odnoszącego się do szeroko rozumianej wiedzy kulturowej;

2. zorientowanego na działanie, dotyczącego szeregu umiejętności interkulturowych;

3. afektywnego, obejmującego postawy oraz nasze nastawianie wobec przedstawicieli innych kultur czy zjawisk interkulturowych jako takich (por. Mihułka 2012b, 2014).

Reasumując dotychczasowe rozważania, można stwierdzić, że kompetencja międzykulturowa stanowi „kompleksową umiejętność czy też zespół zinternalizowanych umiejętności funkcjonowania i radzenia sobie w nowych, trudnych, przebiegających w kontekście wielokulturowości sytuacjach komunikacyjnych" (Mihułka, 2012b: 107). Jej znaczenie dla procesu nauczania/uczenia się języków obcych jest tym bardziej godne podkreślenia, że pełni ona decydującą rolę we wszelkiego rodzaju kontaktach między rodzimymi i nierodzimymi użytkownikami danego języka. Ci ostatni, np. z powodu braku dostosowania formy komunikatu językowego do statusu interlokutora, mogą ograniczyć kontakty z daną osobą czy wręcz ich zaniechać. Tego typu sytuacje mogą prowadzić do powstawania nieporozumień, a nawet konfliktów interkulturowych, których powodów mogą potencjalnie dostarczać wszelkiego rodzaju czynniki sprzyjające występowaniu różnic między poszczególnymi kulturami (por. np. Zając, 2012). Niedostateczna znajomość kulturowych wzorów funkcjonowania danego języka może zatem bezpośrednio skutkować niepowodzeniami komunikacyjnymi i interakcyjnymi, co z kolei może wywołać u osoby uczącej się nie tylko niechęć do dalszej nauki danego języka, ale również lęk przed nawiązywaniem kontaktów w języku docelowym czy niepokój towarzyszący 
obcowaniu z daną kulturą. Stąd też kształcenie kompetencji międzykulturowej wydaje się nabierać szczególnego znaczenia w sytuacjach, w których osoba ucząca się będzie stała przed koniecznością wykorzystywania swoich umiejętności językowych w życiu codziennym danej społeczności językowo-kulturowej, stając się na krótszy lub dłuższy okres jej członkiem.

W kontekście kształcenia uniwersyteckiego takich okazji dostarczają coraz popularniejsze wśród polskich studentów wyjazdy na uczelnie partnerskie, gdzie w zależności od rodzaju podpisanej między uczelniami umowy mogą oni realizować część studiów lub odbyć praktyki zawodowe. Jednym z najpopularniejszych programów międzynarodowych tego typu jest program Erasmus+ będący kontynuacją programu Erasmus na lata 2014-2020, który stanowi jeden z najnowszych programów zatwierdzonych przez Parlament Europejski na rzecz „kształcenia, szkolenia, młodzieży i sportu”. Jak pokazują statystyki opracowane przez Fundację Rozwoju Systemu Edukacji (Erasmus w liczbach - publikacja online), od początku istnienia programu Erasmus do 2013 roku z możliwości wyjazdów na studia lub praktyki studenckie skorzystało łącznie prawie 140000 polskich studentów, a liczba wyjeżdżających jest z roku na rok coraz wyższa. Dla wielu studentów możliwość skorzystania z udziału w tego rodzaju wymianie studenckiej stanowi doskonałą okazję do zetknięcia się z autentycznym zastosowaniem danego języka obcego w naturalnych sytuacjach komunikacyjnych. Oczywiście nie jest to jedyna forma kontaktów umożliwiająca autentyczne wykorzystanie języka docelowego, z jakiej korzystają lub mogą korzystać uczniowie szkół wyższych: dorywcza lub stała praca zarobkowa, wyjazdy turystyczne, realne i wirtualne kontakty towarzyskie itd. Zdobycie wiedzy oraz umiejętności ułatwiających adaptację oraz skuteczne funkcjonowanie w docelowej rzeczywistości językowo-kulturowej staje się zatem dla wielu z nich priorytetowym celem nauki języka obcego. Pozostaje jedynie kwestia doboru metod kształcenia kompetencji międzykulturowych, które zgodnie z aktualnymi trendami w dydaktyce języków obcych mogą się opierać nie tylko na tradycyjnych technikach nauczania, ale również na szeroko rozumianych technikach kształcenia na odległość. W dalszej części artykułu przyjrzymy się, w jaki sposób oraz w jakim zakresie techniki te są wykorzystywane w pracy nad rozwojem omawianej przez nas kompetencji, na podstawie analizy wybranych kursów e-learningowych dedykowanych studentom szkół wyższych. 


\section{Badanie porównawcze wybranych kursów e-learningowych}

\subsection{Cele i procedura badawcza}

Celem badania była ocena zawartości merytorycznej wybranych kursów e-learningowych przygotowanych na potrzeby kształcenia studentów w trzech wybranych wyższych uczelniach - na Uniwersytecie Śląskim, Uniwersytecie Marii Curie-Skłodowskiej oraz Uniwersytecie SWPS w Warszawie - pod kątem możliwości rozwijania kompetencji interkulturowej studentów podczas procesu uczenia się języka obcego. W szczególności analiza obejmowała zakres tematyczny kursów, sposób organizacji modułów, sposób zaplanowania sekwencji jednostki lekcyjnej oraz charakterystykę układu glottodydaktycznego z uwzględnieniem roli nauczyciela, ucznia i typu interakcji. W wyniku badania oczekiwano możliwości sformułowania zaleceń aplikatywnych o charakterze merytorycznym, głównie z uwagi na fakt, że dostępna literatura poświęcona projektowaniu kursów e-learningowych (np. Czarkowski, 2012; Plebańska, 2011) w niewielkim stopniu skupia się na specyfice procesu glottodydaktyczno-interkulturowego $w$ realiach edukacji na odległość.

\subsection{Charakterystyka materiału badawczego}

Analizie poddano 10 kursów e-learningowych przygotowanych na platformie Moodle na potrzeby kształcenia studentów na trzech wspomnianych uniwersytetach. Kursy zostały opracowane przez różnych autorów, m.in. doktorantów studiów neofilologicznych, magistrantów przygotowujących prace magisterskie z wykorzystania e-learningu w kształceniu językowym oraz uczestników zajęć fakultatywnych na studiach drugiego stopnia, a więc charakteryzowały się różnorodnym poziomem profesjonalizmu. Osobnym przedmiotem analizy były dwa kursy „Nie taki Erasmus straszny - kraje angielskiego oraz francuskiego obszaru językowego", przygotowane dla studentów Uniwersytetu Śląskiego przez firmę zewnętrzną wyłonioną w przetargu w ramach projektu „Uniwersytet Partnerem Gospodarki Opartej na Wiedzy”, współfinansowanego ze środków Unii Europejskiej.

\subsection{Wyniki}

\subsubsection{Cele i zakresy tematyczne kursów}

Analizowane kursy e-learningowe pokazują dosyć szeroki wachlarz ujęć kompetencji interkulturowej, począwszy od bardziej tradycyjnego podejścia nakierowanego 
na przekazywanie elementów wiedzy o wybranych aspektach kultury wyłącznie kraju docelowego, przez pokazywanie tych samych elementów kultury w kraju pochodzenia uczniów i kraju nauczanego języka, aż do kursów kształtujących również postawy i umiejętności wchodzące w skład kompetencji interkulturowej. Dla przykładu kurs „Nie taki Erasmus straszny...” jest podzielony na dziewięć modułów, zawierających lekcje w formacie SCORM, kwizy Moodle, kwizy HotPotatoes, strony wprowadzające cele i zawartość treściową modułu:

- Geography, Geopolitics and History (geografia, geopolityka i historia);

- Social Care (opieka społeczna);

- Healthcare (opieka zdrowotna);

- Education (edukacja);

- Manners (zwyczaje życia codziennego);

- Religion (religia);

- Holidays and special occasions (święta);

- Festivals and cultural events (festiwale i wydarzenia kulturalne);

- Heritage (dziedzictwo).

Wobec uniwersalnej akceptacji interkulturowej kompetencji komunikacyjnej jako podstawowego celu kształcenia językowego, składającej się z wiedzy, umiejętności i postaw, zawężenie kursu do elementów wiedzy byłoby dalece niewystarczające. Można więc rozważyć włączenie do każdego modułu 12 zadań rozumienia tekstu czytanego, gdzie teksty będą prezentowały określone postawy (np. otwartości, tolerancji wobec innych kultur) będące elementem składowym interkulturowej kompetencji komunikacyjnej (Byram, 1997; Byram, 2008; Byram i Planet, 1999), a więc połączenie w ten sposób poszerzania wiedzy oraz kształtowania postaw wchodzących w skład kompetencji interkulturowej.

Dobór tematów kursów generalnie odzwierciedla współczesne rozumienie kultury jako pojęcia obejmującego zarówno instytucje państwowe, elementy geografii, historii, polityki, a więc tzw. Kulturę przez duże „K" (big C culture), określaną również mianem kultury osiqgnnięć danej nacji (achievement culture), jak i aspekty życia codziennego, nierozerwalnie związane z elementami zachowań, zwyczajów, sposobów spędzania wolnego czasu, typowych sposobów podróżowania itd. (kultura przez małe „k”, little c culture; kultura zachowań, behaviour culture - Stempleski i Tomalin, 1993). W wielu analizowanych kursach przeważa ten drugi obszar kultury, dzięki czemu nabierają one bardziej praktycznego charakteru, dając uczestnikom niezbędne wiadomości umożliwiające funkcjonowanie w sytuacjach życia codziennego w krajach kultury docelowej (np. kurs językowo-kulturowy „Key to Key Competences” czy „Intercultural Competence Course” zrealizowane w UMCS). 


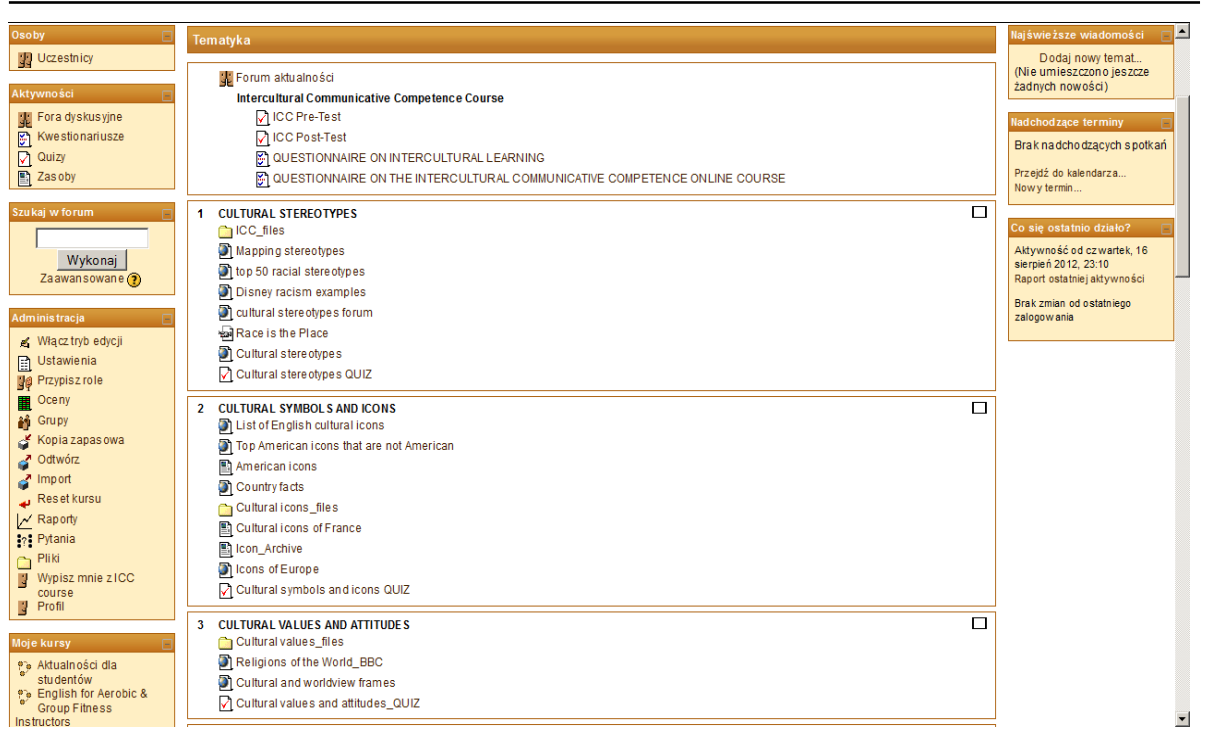

Rysunek 1: Obszary kompetencji interkulturowej realizowane na kursie „Intercultural Competence Course" (UMCS, 2010).

Warto w tym miejscu zwrócić uwagę na problem definicji pojęcia „kraje angielskiego/francuskiego/niemieckiego obszaru językowego" oraz jego realizacji w analizowanych kursach. Tradycyjnie zarówno w podręcznikach, jak i w wielu analizowanych kursach j. angielskiego jako obszar doboru treściowego przyjmowano krainy, z których składa się Wielka Brytania, a więc Anglii, Walii, Szkocji, Irlandii Północnej i Republiki Irlandii. Wydaje się jednak, że jest to sformułowanie mało precyzyjne - współcześnie, w dobie globalizacji, można oczekiwać również przynajmniej częściowego wprowadzenia tematyki związanej ze Stanami Zjednoczonymi, Australią, Kanadą, Nową Zelandią czy Republiką Południowej Afryki jako krajami należącymi do wewnętrznego kręgu (Inner Circle) kultury anglosaskiej (Kachru, 1990). W ramach kursu interkulturowego można więc pokusić się o bardziej przekrojowe podejście włączające porównania wielu krajów zamiast eksploracji szczegółów najbardziej prototypowych państw. Interesującym przykładem idącym w tym kierunku jest zrealizowany w UMCS kurs „Canada: An Introduction for Poles”, zmierzający do poszerzenia wiedzy kulturowej uczniów filologii o zagadnienia związane z Kanadą, skupiający się w szczególności na roli i znaczeniu państwa, podstawowych informacjach z zakresu historii i kultury, mitach i legendach związanych z terytoriami północnymi czy roli kobiet we współczesnej Kanadzie.

Równie interesującym pomysłem konstrukcyjnym, ukazującym innowacyjność $w$ doborze treści interkulturowych, jest wgląd w kulturę poprzez język. Kurs „British English and American English” (UMCS, 2016) uwrażliwia uczniów na różnice 
fonetyczne, leksykalne i gramatyczne między dwiema głównymi odmianami języka angielskiego, wykorzystując przy tym artefakty kultury (nagrania wideo, reklamy w formie obrazków, nagłówki gazet). Tego typu podejście pozwala na równoczesne nabywanie kompetencji językowej i wiedzy kulturowej.
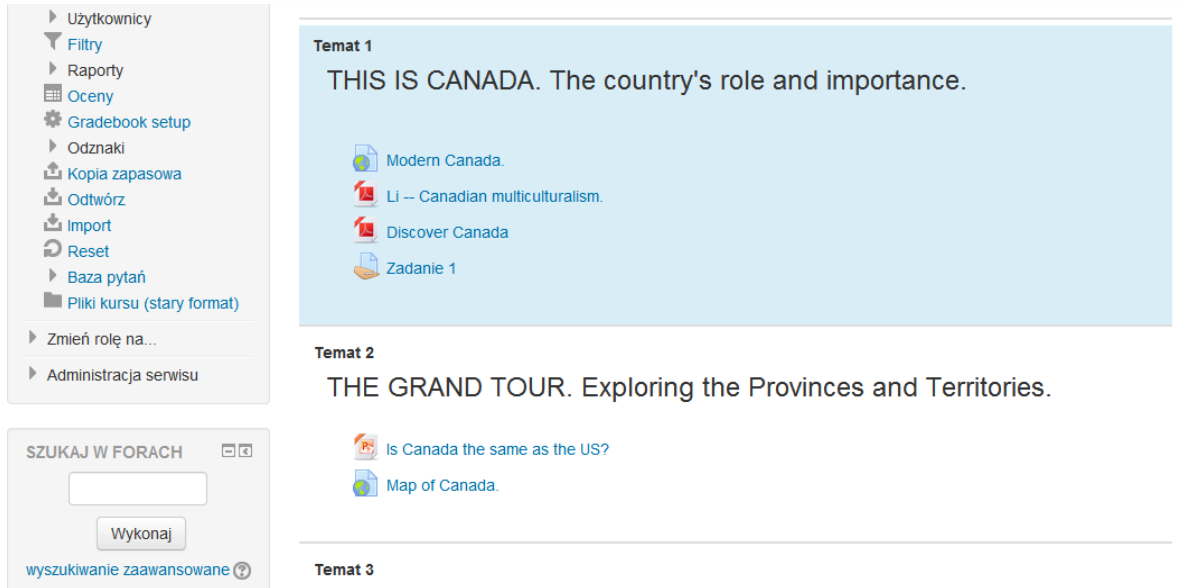

A NATION IS BORN. A brief journey through Canadian history.

Canada's history.
Canadian history QUIZ

Rysunek 2: Trzy tematy kursu „Canada: An Introduction for Poles” (UMCS, 2014).

Analizując sposób gradacji treści interkulturowych w wybranym korpusie kursów e-learningowych, warto zwrócić uwagę na podejście typu „opowiadanie historii" (storyline approach), w którym poszczególne moduły kursu są ze sobą powiązane przez logiczny ciąg wydarzeń z danej dziedziny. Tego typu zabieg konstrukcyjny zastosowali autorzy „Wedding Preparation Course” (USWPS, 2014), pokazującego sposób przygotowania do wesela w krajach anglojęzycznych. Uczeń prowadzony jest krok po kroku przez poszczególne fazy przygotowań, począwszy od planowania budżetu i wybór sukni ślubnej po sposób usadzenia gości przy stole. Wydaje się, że tego typu działanie zwiększa spójność wewnętrzną kursu, a co za tym idzie, wzmacnia zainteresowanie ucznia tematyką kursu i zwiększa motywację do przerabiania kolejnych partii materiału. 


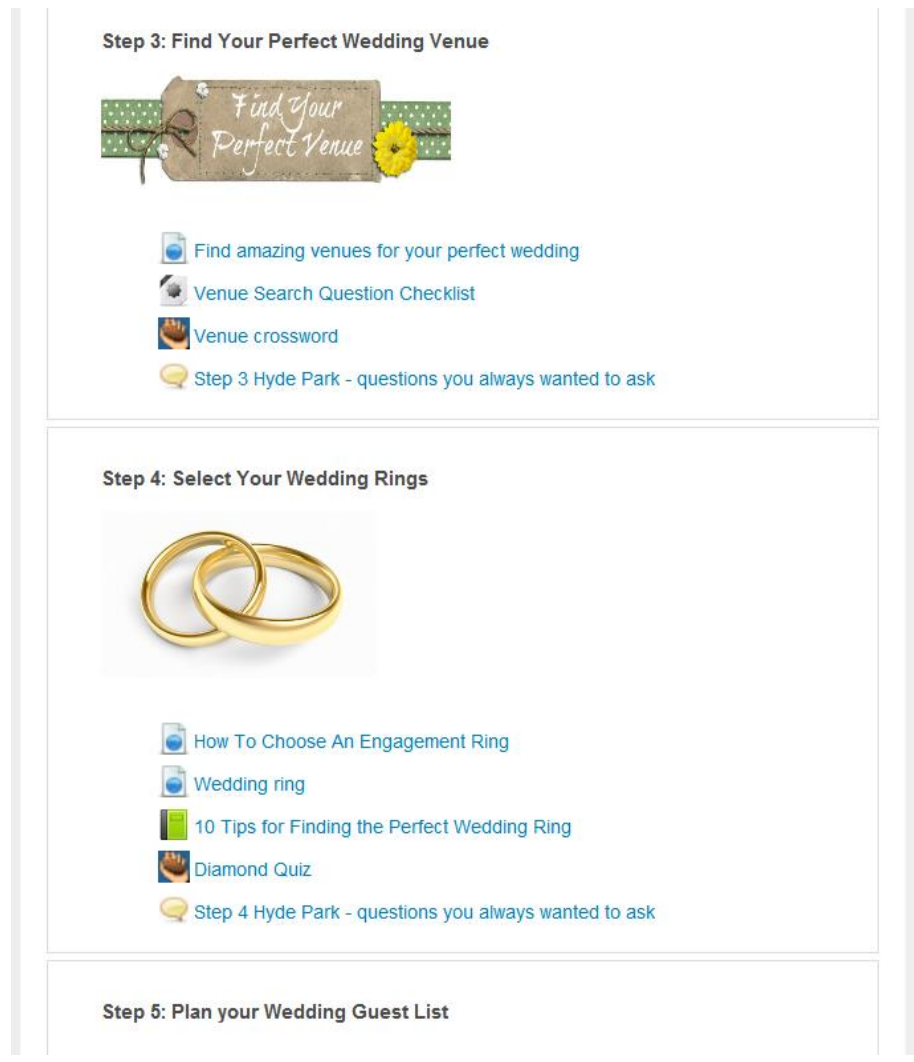

Rysunek 3: Fragment kursu „Wedding Preparation Course” wykorzystującego podejście oparte na opowiadaniu historii (USWPS, 2014).

\subsubsection{Struktura modułów, typy ćwiczeń, sposób realizacji sekwencji lekcji}

Na realizację wyżej wymienionych aspektów ogromny wpływ ma środowisko komputerowe, w którym realizowany jest kurs, oraz koncepcja sposobu użytkowania materiałów po ich opracowaniu. Typy ćwiczeń są zatem zdeterminowane przez zakres możliwości technicznych dostępnych dla autorów kursu, uniemożliwiając im często realizację bardziej wyrafinowanych czy wieloetapowych ćwiczeń. Ograniczenia narzucone przez wybrane środowisko pracy mogą, niestety, negatywnie wpłynąć na jakość opracowanego kursu językowego - w takim modelu pracy autorzy starają się opracować to, co jest wykonalne w ramach aktywności platformy, a niekoniecznie to, co byłoby najbardziej korzystne dla przekazania danego aspektu wiedzy kulturowej czy umiejętności interkulturowych.

Wszystkie analizowane kursy były realizowane na platformie Moodle, która w pewnym sensie zmonopolizowała e-learning w dydaktyce akademickiej 
w Polsce. Większość kursów wykorzystywała wyłącznie aktywności zawarte na platformie oraz łącza do materiałów zewnętrznych, dwa kursy "Nie taki Erasmus straszny..." zawierały gotowe pakiety wykonane w standardzie SCORM w środowisku Flash i zaimportowane na platformę Moodle.

Moduły kursu powinny mieć jednolitą strukturę, zarówno jeśli chodzi o nazwy części, jak i typy zasobów, choć nie zawsze było to regułą. W większości również ilość zasobów w poszczególnych modułach jest wyrównana. Główne części prototypowego modułu to:

- $\quad$ wprowadzenie (introduction), składające się z krótkiego wymienienia celów modułu, testu wstępnego i tematu do dyskusji;

- lekcja (lesson), zawierająca pewną ilość treści podanych na poszczególnych stronach, całość skompilowana w moduły SCORM lub sekwencje materiałów i aktywności zorganizowane np. przy pomocy etykiet;

- utrwalenie (practice), ze znaczną liczbą kwizów Moodle lub HotPotatoes różnego typu (krzyżówki, testy luk, testy wielokrotnego wyboru itd.) wspomaganych elementami multimedialnymi (obrazki, filmy);

- test końcowy, o ograniczonej liczbie podejść (1) oraz czasie wykonania (10 minut).

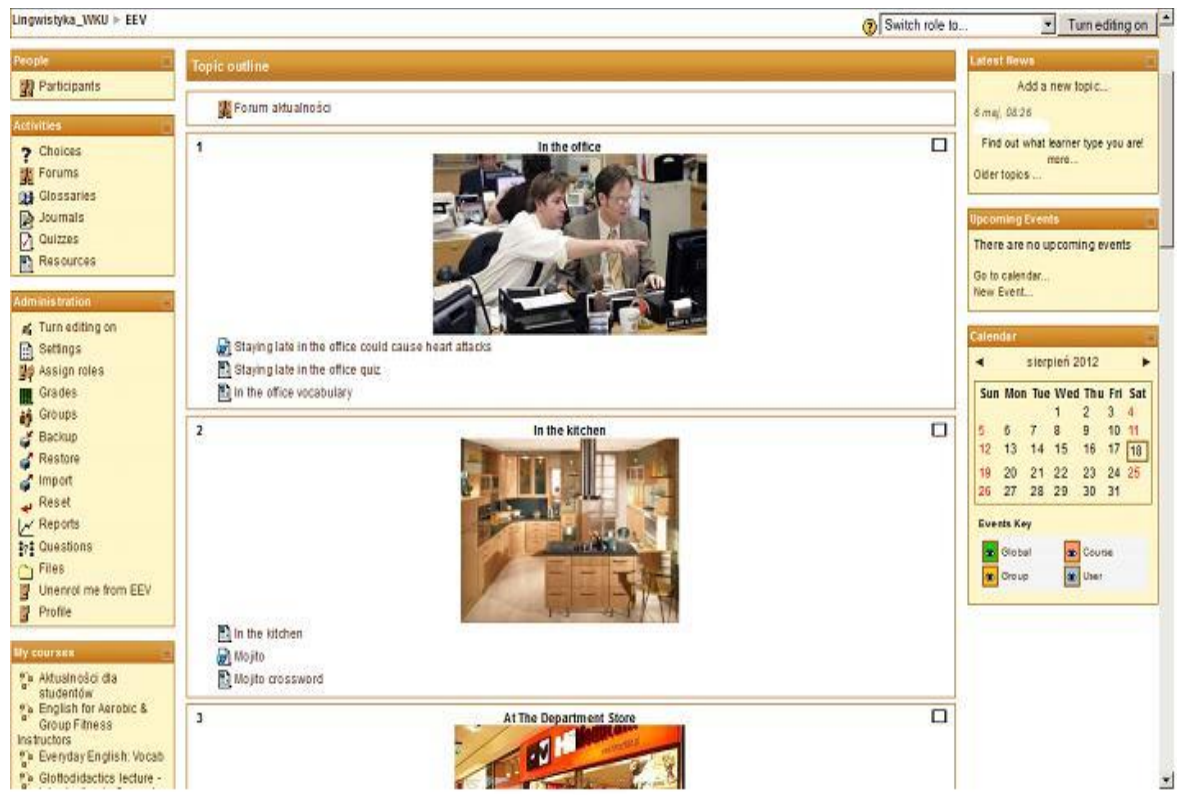

Rysunek 4. Układ kursu „Everyday English” (UMCS, 2010).

Struktura modułów z podziałem na wprowadzenie, lekcję, utrwalenie i test końcowy zastosowana w obu kursach „Nie taki Erasmus straszny” przygotowanych 
przez Uniwersytet Śląski może być właściwa w przypadku przedmiotów niejęzykowych, w których element utrwalenia może następować linearnie po podaniu wiedzy. W przypadku jednak kształcenia językowego czy kształtowania interkulturowej kompetencji komunikacyjnej za pośrednictwem języka obcego bardziej uzasadnione byłoby wyodrębnienie minisekwencji poświęconych poszczególnym tematom w obrębie modułów, w których to minisekwencjach znalazłyby się wszystkie ww. elementy (rozgrzewka językowa, lekcja, utrwalenie). Wydaje się, że seria takich minisekwencji, noszących tytuły wskazujące na ich zawartość, pozwoliłaby na lepszą organizację procesu uczenia się.

W kursie e-learningowym powinna występować pewnego rodzaju część wprowadzająca, w której uczeń powinien dowiedzieć się, jakie cele zostaną zrealizowane, jakie informacje nabędzie, jakie teksty i formy pracy napotka w module i ile czasu powinien na niego poświęcić. Innym przydatnym elementem jest test wstępny, spełniający rolę swego rodzaju rozgrzewki językowokulturowej, służąc niezbędnej aktywizacji struktur pojęciowych i środków leksykalnych posiadanych już przez ucznia.

Na część właściwą modułu najczęściej może się składać seria wieloekranowych lekcji/pakietów SCORM lub też lekcji przygotowanych na platformie Moodle z wykorzystaniem aktywności „Lekcja” lub „Książka”, podających elementy wiedzy wspomagane obrazkami, nagraniami wideo czy rozwijanymi dymkami z dodatkowymi informacjami umieszczonymi na mapach. Tego typu lekcje powinny być opracowane w możliwie atrakcyjny graficznie sposób, z użyciem różnorodnych materiałów multimedialnych wspomagających zrozumienie tekstu, choć przy świadomości ograniczeń technicznych (np. zbyt dużo multimediów utrudniających ładowanie strony). Warto również ujednolicić formę użycia języka w całej lekcji - jeżeli teksty i polecenia są wyłącznie w języku angielskim, podobnie powinno być z informacjami zwrotnymi dla ucznia czy wiadomościami systemowymi (np. „tutaj wpisz swój tekst”). Inne wymogi strukturalno-formalne to ujednolicenie ilości tekstu na jednej stronie, układu tekstu (np. obrazki tylko po lewej stronie, a tekst po prawej) oraz sposobu sprawdzania (pytanie na zrozumienie na dole każdego ekranu, bardziej rozbudowane zadanie na zrozumienie po serii ekranów itd.), a także nadawanie właściwych tytułów poszczególnym elementom czy kwizom.

W wielu analizowanych kursach lekcje czy zestawy materiałów opierają się głównie na sprawności rozumienia tekstu czytanego, a w szczególności czytania selektywnego. Warto jednak rozważyć aktywizację innych mikrosprawności czy większy nacisk na rozumienie ze słuchu. Częstym błędem jest również brak należytej kontroli nad poziomem językowym materiałów w poszczególnych modułach - np. w kursie „Nie taki Erasmus straszny - j. angielski” lekcje w module 1 były przeładowane i trudniejsze językowo, a np. materiały w 
module 7 cechowały się dużo niższym stopniem trudności. Podobnie analizowany kurs kulturowy z języka rosyjskiego „Культура России” (UMCS, 2012) pokazywał wyraźną dysproporcję pomiędzy ilością zasobów w poszczególnych modułach oraz brak wewnętrznego ustrukturyzowania modułów, co pozwoliłoby uczniowi lepiej organizować własną pracę na platformie. Struktura wewnętrzna tematu/modułu może być realizowana poprzez nagłówki (np. „Materiały do pracy własnej”, „Dodatkowe zasoby”, „Ćwiczenia interaktywne”), krótkie opisy poszczególnych etapów modułu, numerację zasobów z uwzględnieniem nagłówków poziomu pierwszego/drugiego/trzeciego, wcięcia zasobów czy też obrazki ilustrujące sposób pracy z poszczególnymi częściami lekcji. Tego typu zabiegi techniczne pomagają uczniowi „odnaleźć się” w module, nawiązują do znanej uczniom struktury podręcznika do nauki języka obcego, wreszcie pokazują zalecaną kolejność pracy z poszczególnymi zasobami, co np. w przypadku rozumienia tekstu czytanego czy rozumienia ze słuchu odgrywa fundamentalne znaczenia dla skuteczności rozwijania sprawności. Przykład wewnętrznej nawigacji przygotowanej dla ucznia w obrębie tematów można znaleźć w kursie „Intercultural Communication" przygotowanym w USWPS (2014; Rysunek 5).

Część ćwiczeniowa analizowanych kursów to najczęściej kwizy Moodle lub HotPotatoes różnego typu (krzyżówki, dopasowanie, wielokrotny wybór, prawda/fałsz). Kwizy są wzbogacone o elementy multimedialne (np. obrazki) i oceniane przy pomocy metody najwyższej/średniej/pierwszej/ostatniej oceny, z limitem podejść bądź ograniczeniem czasowym (lub bez nich). Niezwykle istotną sprawą jest w tym momencie nadanie określonego profilu poszczególnym kwizom, a więc odróżnienie kwizów mających na celu nauczenie ucznia od tych sprawdzających jego/jej wiedzę/umiejętności. Ma to miejsce poprzez dostosowanie sposobu i czasu wyświetlania informacji zwrotnej, poprawnych odpowiedzi czy łącz do materiałów wyjaśniających, stosowanie ograniczenia czasowego, limitowanie liczby podejść czy określanie sposobu ustalania oceny końcowej.

Analizując dobór aktywności wykorzystanych w analizowanych kursach, nie sposób nie zauważyć w wielu z nich braku słownika lub kompendium wiedzy kulturowej, który można dosyć łatwo zrealizować przy pomocy aktywności „Słownik" platformy Moodle. Obecność kompendium najważniejszych postaci, miejsc i pojęć odnoszących się do wybranych aspektów kultury, które nie byłoby przypisane do danego modułu kursu, ale mogłoby być alfabetycznie przeszukiwane $w$ dowolnym momencie kursu, pozwoliłoby na lepszą organizację wiedzy i łatwiejszy do niej dostęp.

Podobnie też analiza materiału badawczego prowadzi do wniosku, że dużo więcej uwagi powinno zostać poświęcone projektowaniu dydaktycznemu w e-learningu, w szczególności dla realizacji określonych formatów ćwiczeń (np. opisywanych przez Bandurę (2007) i zaadaptowanych do typu interakcji używanego 
w danym kursie). Analogicznie do modeli używanych w planowaniu lekcji języka obcego, jak Autentyczne użycie - Ograniczone użycie - Wyjaśnienie ( $A u$ thentic use - Restricted use - Clarification; Scrivener, 1994), Zaangażowanie Poznawanie - Aktywizacja (Engage - Study - Activate; Harmer, 1998) czy Obserwacja - Hipoteza - Eksperymentowanie (OHE; Lewis, 1993), powinny zostać opracowane podobne schematy planowania sekwencji dydaktycznych w e-learningowych materiałach rozwijających kompetencję interkulturową. Modelowym przykładem dobrze opracowanego formatu sekwencji dydaktycznej, na wzór którego należałoby zaadaptować ćwiczenia interkulturowe, są tu formaty typu WebQuest (Dodge, 1995, 2002; Fisher, 2002; Godwin-Jones, 2004; McNierney, 2006; Johnson, Vidoni i Kongrith, 2002; Liu i Edwards 2002; Milman, 2003), „zapytaj eksperta” (ask-an-expert; Luzon Marco, 2002), „wirtualne wycieczki” (virtual telefieldtrips; Luzon Marco 2001b) czy „poszukiwania skarbów” (treasure hunts; Luzon Marco, 2001a).

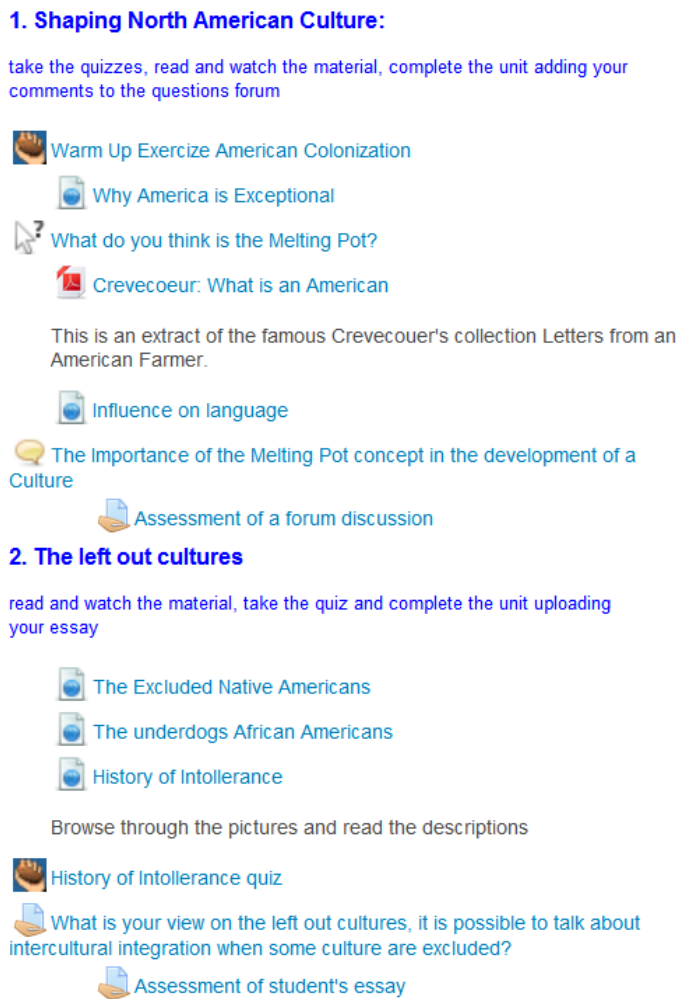

Rysunek 5: Struktura tematu „The Melting Pot” w kursie „Intercultural Communication” (USWPS, 2014) ułatwiająca uczniowi realizację procesu samodzielnej nauki. 


\subsubsection{Preferowany układ glottodydaktyczny}

Realizacja procesu uczenia się w większości analizowanych kursów odbywa się w trybie automatycznego samouczka, co determinuje dobór aktywności platformy Moodle. Przykładowo w kursie „Nie taki Erasmus straszny...” lekcje przekazujące wybrane aspekty wiedzy o krajach angielskiego obszaru językowego czy kwizy sprawdzające stopień opanowania tej wiedzy to naturalne elementy składowe tego typu kursu. W przypadku kursu wyłącznie do pracy własnej, bez udziału nauczyciela, lekcje i kwizy powinny być uzupełnione przez słowniczek, ewentualnie książki.

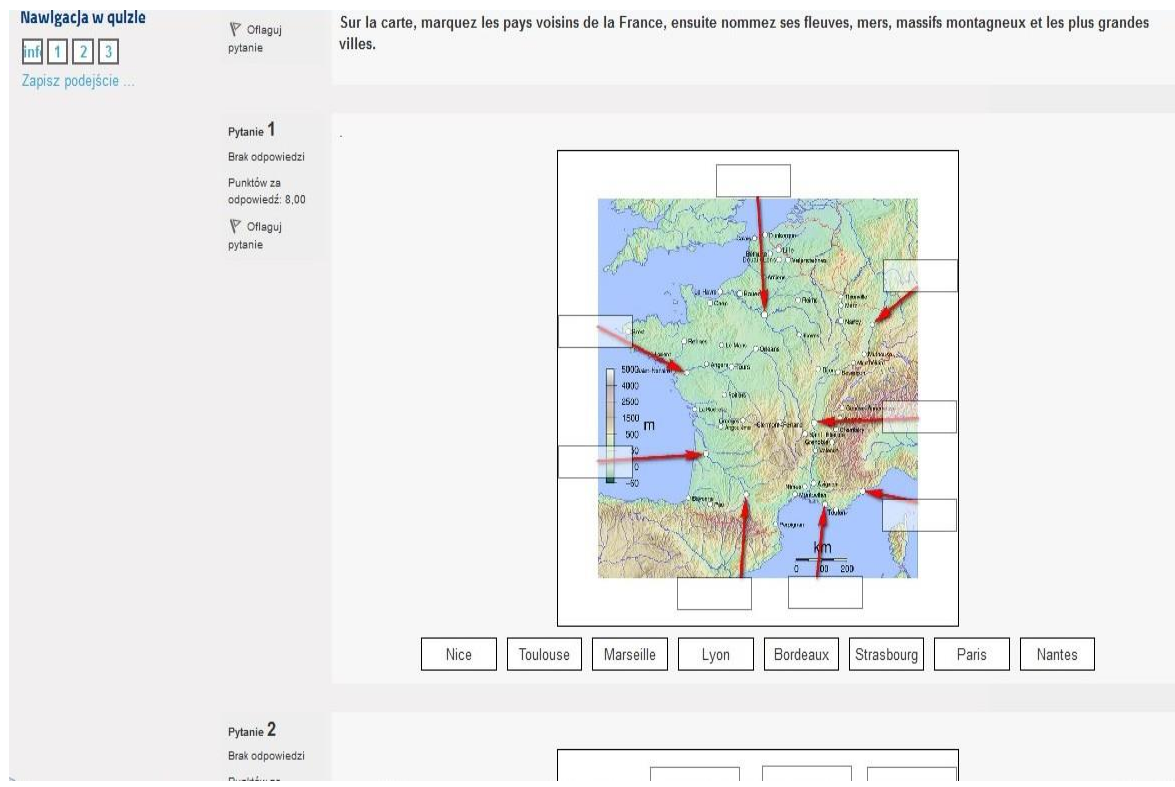

Rysunek 6: Przykładowy test z kursu „Nie taki Erasmus straszny - kraje francuskiego obszaru językowego" (UŚ, 2014).

E-learningowy samouczek to kurs, w którym uczeń pracuje z podanymi mu materiałami, udziela odpowiedzi, które są oceniane według podanego wcześniej klucza. Rolą nauczyciela jest opracowanie materiałów, wprowadzenie możliwie precyzyjnego klucza odpowiedzi, zaprogramowanie informacji zwrotnej i opracowanie sekwencji pracy. Istotne w tego typu układzie glottodydaktycznym jest umiejętne korzystanie z różnych modeli oceniania w zależności od fazy lekcji. Kwizy fazy utrwalenia mają nieograniczoną liczbę podejść, a zapisywana jest najwyższa uzyskana ocena. Dzięki temu uczeń ma możliwość ponownego przerobienia lekcji i wykonania kwizu jeszcze raz bez konsekwencji dla uzyskanej oceny, w celu pełniejszego opanowania różnych aspektów wiedzy. Z kolei zarówno test wstępny, jak i końcowy mają pewne ograniczenia, 
umożliwiające bardziej precyzyjny pomiar wiedzy ucznia na wejściu i wyjściu. W przypadku testu wstępnego można rozważyć ograniczenie liczby podejść (np. 1) oraz limitu czasu (np. 5 minut) oraz, co ważne, zapewnić ucznia, że wynik tego testu nie będzie miał wpływu na końcową ocenę z kursu. Podobne zasady można ustalić dla testu końcowego, z tą różnicą, że jego rezultaty są zapisywane w dzienniku ocen. O ile ustawienia te są właściwe dla rozróżnienia testów utrwalających, testu wstępnego i końcowego, można zastanowić się, czy w przypadku testów utrwalających (wszystkich lub niektórych) nie warto byłoby zastosować metody oceny średniej, aby ci uczniowie, którzy lepiej opanowali lekcje (i w rezultacie potrzebują mniejszej liczby podejść do kwizu w celu jego ukończenia) uzyskali wyższą ocenę końcową.

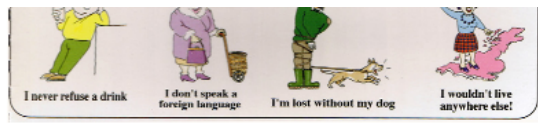

\section{Europe as seen by British:}

take the warm up quiz, read and watch the material, complete the unit adding your comments to the questions forum

Warm Up Exercize Europe vs UK

Is UK influential in Europe?

Is UK role in Europe a barrier for business ?

21st century debate in UK

How is the role of UK in Europe important for European Union future?

Assessment of a forum discussion

2. Influence of stereotypes:

take the quizzes, read and watch the material, complete the unit uploading your essay

?hat do you think is a stereotype?

- Europe according to British, Stereotypes map

British Stereotypes

e Effects of a Cultural Stereotype in the Workplace

How to Reduce Workplace Stereotyping

Fill the Gaps, UK stereotypes

How do you think stereotypes influence the business relationships between UK and the rest of Europe

Assessment of student's essay

Rysunek 7: Temat „Europe+UK” z kursu „Intercultural Communication” (USWPS, 2014) pokazujący ocenianie poprzez zadania opisowe oraz fora dyskusyjne.

Ponieważ ocena kompetencji interkulturowej nie może się opierać jedynie na automatycznie sprawdzanych zadaniach zamkniętych, testujących głównie 
elementy wiedzy kulturowej, podczas rozwijania umiejętności interkulturowych w e-learningu warto zwiększyć rolę nauczyciela odpowiadającego na aktywności uczniów, np. w prywatnych wirtualnych dzienniczkach czy na forach. W takim modelu kursu interakcja ucznia następuje zarówno z materiałami za pośrednictwem platformy (nauka na podstawie zamieszczonych zasobów, sprawdzanie postępów przez zautomatyzowane kwizy i lekcje), jak również z nauczycielem i innymi uczniami poprzez dzienniczki czy fora dyskusyjne.

W przypadku zakładania możliwej wirtualnej interakcji pomiędzy uczniami korzystającymi z kursu, warto zadać sobie pytanie, czy nie dodać również aktywności komunikacyjnych typu forum czy wiki nie tylko w fazie wstępnej modułu, ale również końcowej. Obecność dyskusji w każdym module, np. w fazie podsumowania, pozwoliłaby na zastosowanie nabytej wiedzy i słownictwa w użyciu języka przy jednoczesnej możliwości kształtowania umiejętności i postaw wchodzących w skład opisywanej wyżej interkulturowej kompetencji komunikacyjnej. Tego typu model interakcyjny odpowiada lepiej na fakt, że współczesna glottodydaktyka kładzie dużo większy nacisk na rolę ucznia w procesie oceniania, dostosowanie sposobu oceniania do jego potrzeb i włączenie ucznia w dokonywanie oceny. Współczesne platformy zdalnego nauczania, takie jak Moodle, oferują wiele aktywności pozwalających na zastosowanie elementów oceniania wzajemnego (peer-assessment) czy samooceny (self-assessment) w procesie nabywania wiedzy (por. Krajka, 2007; Krajka, 2008; Marczak i Krajka, 2016). Można wspomnieć tu chociażby takie elementy jak wzajemne ocenianie postów na forach dyskusyjnych, ocenianie wpisów do słownika czy też samoocenę realizowaną w formie ankiety czy wpisów w dzienniku. Zastosowanie technik oceny wzajemnej warto zastosować w kursach interakcyjnych w połączeniu z technikami testowymi. Elementy samooceny można wprowadzić poprzez umieszczenie ankiet lub nieocenianych kwizów pozwalających uczniowi na odniesienie swojej wiedzy, umiejętności i postaw do celów zakładanych $w$ danym module. $Z$ kolei regularne wpisy do dziennika, np. na koniec każdego modułu, pozwoliłyby uczniowi nie tylko na rozwijanie pisemnej kompetencji komunikacyjnej, ale, co ważniejsze, na indywidualną refleksję nad procesem rozwijania kompetencji interkulturowej, pozwalającą na uzyskanie niezbędnej świadomości krytycznej (critical awareness). Wydaje się również, że umiejętne określenie tematyki wpisów dziennika zachęciłoby ucznia do przeprowadzenia porównania pomiędzy elementami kultury kraju nauczanego języka oraz kultury rodzimej w celu nabycia umiejętności interpretowania i porównywania obu kultur (skills of interpreting and relating, skills of comparison, skills of discovery and interaction) (Byram, 1997). 


\section{Wnioski końcowe}

Wraz z powszechną dostępnością platform e-learningowych (głównie Moodle) oraz wzrastającymi umiejętnościami technicznymi studentów, doktorantów i wykładowców wyższych uczelni wspomaganie kształcenia językowo-kulturowego przy pomocy dedykowanej obudowy multimedialnej nie napotyka większych przeszkód natury technicznej czy finansowej. Jak pokazuje analiza, zupełnie inaczej wygląda kwestia jakości merytorycznej. Główny nacisk w kształceniu studentów, doktorantów czy wykładowców neofilologii powinien być położony na problematykę projektowania dydaktycznego w e-learningu. Umiejętności właściwej diagnozy potrzeb, zarówno tych wyartykułowanych przez potencjalnych lub realnych użytkowników, jak i ustalonych przez czynniki zewnętrzne, umiejętności odpowiedniego planowania kursu, ewaluacji i dydaktyzacji materiałów, wreszcie ich odpowiedniej obudowy aktywnościami platformy, wymagają dalszych badań w celu stworzenia kodeksu dobrej praktyki. Można mieć nadzieję, że nasz artykuł, skupiający się głównie na kwestiach opisu kompetencji interkulturowej, wyboru obszarów, sposobów projektowania układu glottodydaktycznego i doboru form oceniania, rozpoczyna wartościową dyskusję w tej materii.

\section{BIBLIOGRAFIA}

Banach, B. 2003. „Tendencje interkulturowe we współczesnej glottodydaktyce”. Języki Obce w Szkole, 3: 3-17.

Bandura, E. 2007. Nauczyciel jako mediator kulturowy. Kraków: Tertium.

Byram, M. i M. T. Planet. 1999. Social Identity and European Dimension. Intercultural Competence through Foreign Language Learning. Strasbourg: Council of Europe.

Byram, M. 1997. Teaching and Assessing Intercultural Communicative Competence. Clevedon: Multilingual Matters.

Byram, M. 2008. From Foreign Language Education to Education for Intercultural Citizenship. Clevedon - Buffalo - Toronto: Multilingual Matters.

Chłopek, Z. 2009. „Nauczanie kultury na lekcjach języka obcego w Polsce: Wyniki badań kwestionariuszowych". Języki Obce w Szkole, 1: 61-68.

Czarkowski, J. J. 2012. E-learning dla dorosłych. Warszawa: Difin.

Dodge, B. 1995. Some thoughts about WebQuests. [online: http://webquest.sdsu.edu/ about_webquests.html; DW 12.12.2015].

Dodge, B. 2002. WebQuest taskonomy: A taxonomy of tasks. [online: http://webquest. sdsu.edu/taskonomy.html; DW 10.07.2014].

Europejski System Opisu Kształcenia Językowego: uczenie się, nauczanie, ocenianie. 2003. Warszawa: Wydawnictwa CODN.

Fisher, T. 2002. Theory into Practice: WebQuests in Geography. Sheffield: Geographical Association. 
Fundacja Rozwoju Systemu Edukacji. Erasmus w liczbach. [online: http://www.erasmus. org.pl/odnosniki-podstawowe/statystyki; DW 12.12.2015].

Godwin-Jones, B. 2004. „Language in action: From WebQuests to Virtual Realities”. Language Learning \& Technology, 8(3): 9-14.

Harmer, J. 1998. How to Teach English: An Introduction to the Practice of English Language Teaching. Harlow: Longman.

Johnson, L., Vidoni, K. i K. Kongrith. 2002. „WebQuests for course delivery and integration training". Society for Information Technology and Teacher Education International Conference, 1: 846-847. [online: http://dl.aace.org/10923; DW 12.12.2015].

Kachru, B. 1990. The Alchemy of English: The Spread, Functions, and Models of Nonnative Englishes. Urbana-Champaign: University of Illinois Press.

Komisja Europejska, 2013. Erasmust. Przewodnik po programie. [online: http://ec.europa. eu/programmes/erasmus-plus/documents/erasmus-plus-programme-guide_pl.pdf; DW 12.12.2015].

Krajka, J. 2007. „Kształtowanie procesu glottodydaktycznego z użyciem Systemów Zarządzania Nauką (Learning Management Systems)". Przegląd Glottodydaktyczny, 23: 37-48.

Krajka, J. 2008: „Ewaluacja efektów kształcenia w platformach nauczania na odległość". (w) W stronę nowoczesnego nauczania języków obcych. (red. M. Jodłowiec, A. Niżegorodcew). Kraków: Tertium, str. 91-106.

Lewis, M. 1993. The Lexical Approach. Hove: Language Teaching Publications.

Liu, J., i C. Edwards. 2002. „WebQuest: An innovative way of applying information resources to furnish performance tasks". World Conference on Educational Multimedia, Hypermedia and Telecommunications, 1: 1146-1149. [online: http:// dl.aace.org/10297; DW 12.12.2015].

Luzon Marco, M. J. 2001a. „Information collection and analysis activities: The treasure hunt”. Teaching English with Technology, 1(4). [online: http://www.tewtjournal.org/VOL\% 201/ISSUE\%204/VOL\%201\%20ISSUE\%204\%20COMPLETE.pdf; DW 12.12.2015].

Luzon Marco, M. J. 2001b. „Information collection and analysis activities: Virtual fieldtrips (tele-fieldtrips)". Teaching English with Technology, 1(5). [online: http:// www.tewtjournal.org/VOL\%201/ISSUE\%205/INTERNET\%20AND\%20ESP.pdf; DW 12.12.2015].

Luzon Marco, M. J. 2002. „"AAsk an expert“ activities: An example of interpersonal exchange”. Teaching English with Technology, nr 2(1). [online: http://www.tewtjournal.org/ VOL\%202/ISSUE\%201/INTERNET\%2OFOR\%20ESP.pdf; DW 12.12.2015].

Mackiewicz, M. (red.). 2005. Dydaktyka języków obcych a kompetencja kulturowa i komunikacja interkulturowa. Poznań: Wydawnictwo Wyższej szkoły Bankowej.

Mackiewicz, M. (red.). 2009. Kompetencja interkulturowa w teorii i praktyce edukacyjnej. Poznań: Wydawnictwo Wyższej szkoły Bankowej.

Marczak, M. i J. Krajka. 2016: „Assessing Intercultural Communicative Competence in Learning Management Systems". (w) Integrating Technology and Culture. Strategies and Innovation in ELT. (red. Md. Mojibur Rahman). Chaura Rasta: Yking Books, str. 295-315. 
McNierney, D. 2006. „WebQuests: Instructional and design techniques”. World Conference on E-Learning in Corp., Govt., Health., \& Higher Ed., 1: 1907-1910. [online: http://dl.aace.org/9707; DW 12.12.2015].

Mihułka, K. 2012a. Rozwój kompetencji interkulturowej w warunkach szkolnych - mity a polska rzeczywistość. Na przykładzie języka niemieckiego jako L3. Rzeszów: Wydawnictwo Uniwersytetu Rzeszowskiego.

Mihułka, K. 2012b. „Sposoby rozwijania kompetencji interkulturowej na lekcji języka obcego". Języki Obce w Szkole, 2: 106-117.

Mihułka, K. 2014. „Dylematy współczesnej glottodydaktyki: język - kultura, interlingwalizm - interkulturowość”. Języki Obce w Szkole, 3: 78-87.

Milman, N. 2003. „WebQuests: A tool for developing teachers' Web design and evaluation skills". Society for Information Technology and Teacher Education International Conference, 1: 2027-2029. [online: http://dl.aace.org/12119; DW 12.12.2015].

Plebańska, M. 2011. E-learning. Tajniki edukacji na odległość. Warszawa: C. H. Beck.

Scrivener, J. 1994. Learning Teaching. Oxford: Heinemann.

Siek-Piskozub, T. 2012. „Międzykulturowa kompetencja komunikacyjna wyzwaniem dla glottodydaktyki”. Lingwistyka Stosowana, 5: 95-108.

Stempleski, S. i B. Tomalin. 1993. Cultural Awareness. Oxford: Oxford University Press. Torenc, M. 2007. Nauczanie międzykulturowe - implikacje glottodydaktyczne. Wrocław: Atut.

Wilczyńska, W. 2002: „Badania interkulturowe w praktyce dydaktycznej”. (w) European Year of Languages 2001. Proceedings of the 3rd CER-FIPLV conference. (red. T. SiekPiskozub). Poznań: Uniwersytet im. Adama Mickiewicza i Motivex, str. 127-137.

Zając, J. 1997. „Od nauczania cywilizacji do refleksji interkulturowej na lekcji języka obcego". Języki Obce w Szkole, 3: 195-199.

Zając, J. 2012. „Kompetencje mediacyjne nauczyciela języków obcych w perspektywie interkulturowej”. Języki Obce w Szkole, 1: 14-21.

Żydek-Bednarczuk, U. 2012. „Kompetencja międzykulturowa w nauczaniu języka polskiego jako obcego". Postscriptum Polonistyczne, 2(10): 19-36.

Żydek-Bednarczuk, U. 2015. Spotkanie kultur. Komunikacja i edukacja międzykulturowa w glottodydaktyce. Katowice: Wydawnictwo UŚ.

Żylińska, M. 2003. „Podejście interkulturowe, czyli o konieczności zmian w nauczaniu języków obcych". Języki Obce w Szkole, 6: 49-62.

\section{Analizowane kursy}

1. Uniwersytet Śląski:

„Nie taki Erasmus straszny - kraje angielskiego obszaru językowego”, http://el.us.edu.pl/ upgow/course/view.php?id=126.

„Nie taki Erasmus straszny - kraje francuskiego obszaru językowego”, http://el.us.edu.pl/ upgow/course/view.php?id=125. 
E-learning w kształceniu kompetencji międzykulturowych na poziomie...

2. Uniwersytet Marii Curie-Skłodowskiej:

„English for Everyday Uses”, http://lingwistyka.kampus.umcs.lublin.pl/moodle/course/ view.php?id=176.

„Культура России”, http://lingwistyka.kampus.umcs.lublin.pl/moodle/course/view.php ?id=120.

„Everyday English: Vocab”, http://lingwistyka.kampus.umcs.lublin.pl/moodle/course/ view.php?id=85.

„Canada: An Introduction for Poles”, http://lingwistyka.kampus.umcs.lublin.pl/moodle/ course/view.php?id=150.

„Key to Key Competences”, http://lingwistyka.kampus.umcs.lublin.pl/moodle/course/ view.php?id=119.

„British English and American English Course”, http://lingwistyka.kampus.umcs.lublin.pl/ moodle/course/view.php?id=118.

3. Uniwersytet SWPS:

„Intercultural Communication”, http://new-e-learning.swps.edu.pl/course/view.php?id=1494.

„Wedding Preparation Course”, http://new-e-learning.swps.edu.pl/course/view.php?id=2200. 